\title{
Educação escolar indígena: um estudo sociolinguístico do nheengatu na comunidade Pisasu Sarusawa do rio Negro, Manaus, $\mathrm{AM}^{1}$
}

\author{
Indigenous school education: A nheengatu sociolinguistic \\ study at Pisasu Sarusawa community in the Negro river, \\ Manaus, AM
}

Ademar dos Santos Lima²

Silvana Andrade Martins ${ }^{2}$

DOI: http://dx.doi.org/10.20435/tellus.v17i33.443

\begin{abstract}
Resumo: Este trabalho tem como objetivo apresentar os resultados de pesquisa da língua nheengatu na comunidade Pisasu Sarusawa do povo Baré, no município de Manaus, Estado do Amazonas. Trata-se de um estudo sobre a situação sociolinguística na escola indígena Puranga Pisasu. As metodologias utilizadas foram abordagem quali-quantitativa, pesquisa de campo e de estudo descritivo, e as técnicas empregadas foram questionário semiestruturado, entrevista e observação participante. A pesquisa faz parte do projeto em andamento "Educação Escolar Indígena: um estudo sociolinguístico do nheengatu no município de Manaus", cujo objetivo final foi avaliar o grau de manutenção, ameaça de deslocamento sociolinguístico e/ou o processo de revitalização da língua nheengatu por meio do ensino oferecido pela escola em questão. Foram pesquisados 128 informantes sobre competências e habilidades na fala do nheengatu. O estudo constatou que, destes, apenas 25, na faixa-etária acima dos 40 anos, falam fluentemente a língua, 38, na faixa-etária entre 20 a 39 anos, apenas entendem e sabem falar algumas palavras, os demais, 65, na faixa-etária de 3 a 19 anos não falam e apenas entendem a língua geral. $O$ estudo verificou também que houve uma descontinuidade na transmissão do nheengatu entre este grupo de falantes, que passaram a falar mais o português. Atualmente, a língua geral passa pelo processo de revitalização na comunidade do povo Baré.
\end{abstract}

Palavras-chave: línguas indígenas; bilinguismo; revitalização.

\footnotetext{
${ }^{1}$ Este artigo foi extraído do primeiro capítulo da dissertação de mestrado denominada "Educação escolar indígena: um estudo sociolinguístico do nheengatu na escola Puranga Pisasu do rio Negro, Manaus, AM".

${ }^{2}$ Universidade do Estado do Amazonas (UEA), Manaus, Amazonas, Brasil.
} 


\begin{abstract}
This paper aims to present the research results of the nheengatu language in the Pisasu Sarusawa community of the Baré people, in the municipality of Manaus, State of Amazonas. It is a study about the sociolinguistic situation in the Puranga Pisasu indigenous school. The methodologies used were qualitative-quantitative approach, field research and descriptive study, and the techniques used were semi-structured questionnaire, interview and participant observation. The research is part of the ongoing project "Indigenous School Education: a sociolinguistic study of nheengatu in the municipality of Manaus", whose final objective was to evaluate the degree of maintenance, threat of sociolinguistic displacement and / or the revitalization process of nheengatu language through of the education offered by the school in question. A total of 128 informants were interviewed on skills and abilities in nheengatu speech. The study found that of these, only 25 , in the age group above 40 years speak fluently the language, 38, in the age group between 20 to 39 years only understand and can speak some words, the others, 65, in the age group ages 3 to 19 do not speak and just understand the general language. The study also verified that there was a discontinuity in the transmission of nheengatu among this group of speakers, who started to speak more Portuguese. Currently, the general language goes through the process of revitalization in the community of the Baré people.
\end{abstract}

Key words: indigenous languages; bilingualism; revitalization.

\title{
1 INTRODUÇÃO
}

A presente pesquisa foi desenvolvida com base nos pressupostos sociolinguísticos e se insere na linha de pesquisa "Linguagem, discurso e práticas sociais", do Curso de Pós-Graduação em Letras e Artes (PPGLA) da Universidade do Estado do Amazonas (UEA). O estudo tem como propósito refletir sobre a Educação Escolar Indígena proposta na legislação específica federal, estadual e municipal tendo como referência uma escola indígena da Comunidade (PISASU SARUSAWA/ NOVA ESPERANÇA) da etnia Baré, localizada no rio Cuieiras, baixo rio Negro, Zona Rural do município de Manaus, Amazonas, tendo como objetivo descrever a situação atual da educação escolar indígena na comunidade supracitada, mais especificamente o processo de ensino-aprendizagem da língua nheengatu (língua boa) no ambiente escolar e averiguar o grau de manutenção, ameaça de deslocamento sociolinguístico e/ou o processo de revitalização. Como já se sabe, a Educação Escolar Indígena foi uma conquista dos povos indígenas do Brasil desde a década de 1980, já prevista pela Constituição Federal (CF) de 1988, nos artigos 210 e 231, que reconhece aos índios o direito às suas línguas, conforme cita no inciso [2으, "O ensino fundamental regular será ministrado em 
língua portuguesa, assegurada às comunidades indígenas, também a utilização de suas línguas maternas e processos próprios de aprendizagem". Assim, a partir do reconhecimento da CF, a sociedade indígena ganha força para debater sobre suas questões sociais, culturais e linguísticas, amparada por lei. Posteriormente, a Lei de Diretrizes e Bases da Educação Nacional (LDB) n. 9.394/96, nos artigos n. 32,78 e 79, sob os quais os povos indígenas, também foram contemplados, além de repor o respeito às suas línguas maternas, a LDB deixa claro que os poderes públicos devem "proporcionar aos índios, suas comunidades e povos a recuperação de suas memórias históricas, a reafirmação de suas identidades étnicas, a valorização de suas línguas e ciências". Dessa forma, os povos indígenas são reconhecidos e valorizados no ambiente educacional, e a escola, por meio da Educação Escolar Indígena, promove assim uma simbiose entre os conhecimentos ocidentais e indígenas e valorização das diversas culturas, bem como, forma cidadãos que respeitem e preservem suas tradições, culturas e línguas, ajudando na preservação étnica de suas comunidades.

No contexto do município de Manaus, Amazonas, também houve alguns avanços em relação às políticas públicas e linguísticas voltadas para a Educação Escolar Indígena, sobretudo, por meio da regularização do Decreto Municipal n. 90/2009, que cria a Gerência de Educação Escolar Indígena (GEEI), cujo objetivo é desenvolver atividades educativas que atendam às reivindicações dos povos indígenas e o cumprimento das políticas públicas voltadas à "educação escolar indígena", especificamente das etnias que vivem no município de Manaus.

A partir desses marcos regulatórios, o governo municipal, através da Secretaria Municipal de Educação de Manaus, implantou quatro escolas indígenas e apoia dezoito espaços culturais nas comunidades indígenas no município. Entretanto, devido à grande diversidade linguística e bastante complexa, o município de Manaus, até então, foi pouco estudado, não sendo, portanto, conhecidos de forma sistemática os fenômenos linguísticos que vêm ocorrendo nas línguas indígenas e, pelo fato de sermos profissional da área de educação nas escolas indígenas do município, nos levaram a escolher o tema Educação Escolar Indígena, com ênfase na língua nheengatu. Na nossa vivência, entendemos que o assunto mereceu ser investigado, pois o conhecimento da situação linguística numa comunidade bilíngue é fundamental para que, a partir de sua verificação, se desenvolvam estratégias para combater possíveis deslocamentos sociolinguísticos e evitar o desaparecimento das línguas. Como 
já se sabe, as línguas indígenas são línguas de minorias étnicas e correm o risco de desaparecerem, pois seu uso é restrito, seus falantes são em número bastante reduzido e só recentemente há uma política do estado para a sua revitalização e uso como línguas de instrução e ensino nas escolas indígenas. A urgência da documentação e descrição dessas línguas é grande e sustenta-se que a produção científica sobre elas contribua para valorizá-las como línguas de expressão legítimas dos povos que as falam, para criar políticas de proteção à diversidade linguística, além de contribuir para as pesquisas sobre o conhecimento tradicional expresso através delas, sendo elas próprias uma das formas de conhecimento tradicional e cultural. Nessa perspectiva, busca-se analisar a problemática da pesquisa em questão: Na comunidade em estudo, as práticas de ensino na escola indígena promovem o fortalecimento do nheengatu?Como se opera o processo de ressignificação do bilinguismo no espaço escolar no contexto social da comunidade em estudo?

A partir dessa análise, algumas questões norteadoras são enfrentadas no desenvolvimento do estudo: Em que consiste o processo de ensino-aprendizagem da língua nheengatu na comunidade Pisasú Sarusawa do rio Negro, Manaus, Amazonas? Quais são as estratégias pedagógicas no plano de ensino da língua nheengatu na comunidade Pisasú Sarusawa do rio Negro, Manaus, Amazonas? Como se dá o processo de ressignificação do bilinguismo no espaço escolar no contexto social da comunidade e como averiguar o grau de manutenção e/ou ameaça de deslocamento sociolinguístico na comunidade Pisasu Sarusawa do rio Negro, Manaus, Amazonas?

Nesse sentido, as hipóteses que nortearam a pesquisa foram formuladas nos seguintes termos: O processo de ensino da língua nheengatu na comunidade Pisasú Sarusawa do município de Manaus como meio para a revitalização da língua;

O processo de ressignificação do bilinguismo no espaço escolar no contexto social da comunidade;

As práticas do ensino-aprendizagem da língua nheengatu como meio para evitar o fenômeno de deslocamento sociolinguístico na comunidade Pisasu Sarusawa do rio Negro, Manaus, Amazonas.

Acredita-se que o esforço teórico para tentar responder a essas questões se justifica na medida em que os resultados da pesquisa podem eventualmente contribuir para uma reflexão crítica sobre o modo como o ensino do nheengatu oferecido nas escolas indígenas, de fato, tem ajudado na manutenção e/ou revitalização da língua indígena. 
Educação escolar indígena: um estudo sociolinguístico do nheengatu na comunidade Pisasu Sarusawa do rio Negro, Manaus, AM

Nesse sentido, a proposta de estudo desenvolvida nesta pesquisa se orienta também para a compreensão do papel histórico-social desempenhado pelo nheengatu no processo de construção social da "identidade coletiva indígena" protagonizado pelo movimento de emergência étnica verificado na comunidade Pisasu Sarusawa. Ou seja, o enfoque analítico se concentra no discurso do "ensino da língua no espaço escolar" com a finalidade de afirmar sua importância como meio de manutenção e revitalização da língua e, consequentemente, implica também o desvendamento dos significados historicamente atribuídos ao nheengatu, tanto no passado histórico quanto na contemporaneidade.

Nessa perspectiva, o objetivo principal da pesquisa é: Analisar como se dá o processo de ensino-aprendizagem da língua nheengatu no espaço escolar da comunidade Pisasú Sarusawa do rio Negro, Amazonas.

Os objetivos mais específicos são: Investigar o processo de ensino-aprendizagem da língua nheengatu no espaço escolar da comunidade Pisasú Sarusawa do rio Negro, Amazonas;

Identificar o processo de ressignificação do bilinguismo no espaço escolar no contexto social da comunidade;

Descrever como se dá a prática do ensino-aprendizagem da língua nheengatu e averiguar o grau de manutenção e/ou ameaça de deslocamento sociolinguístico na comunidade Pisasú Sarusawa do rio Negro, Manaus, Amazonas.

A pesquisa em seu desenvolvimento metodológico seguiu os seguintes passos:

Inicialmente, foram realizadas leituras correspondentes à revisão de literatura do assunto abordado, a partir do levantamento de dados bibliográficos sobre o tema, especificamente sobre Educação Escolar Indígena e língua pesquisada. Os dados analisados foram os de: Renault-Lescure (1990), Pacheco (2009), Pinheiro (2011) e da situação sociolinguística nas escolas indígenas de São Gabriel, de Melgueiro (2012).

A natureza da pesquisa foi de caráter qualitativo, embora dados quantitativos tenham sido levantados e avaliados para a interpretação e construção das conclusões. Utilizamos a técnica da observação participante, considerando a definição constante em Queiroz et al (2007):

A observação participante é uma técnica muito utilizada pelos pesquisadores que adotam a abordagem qualitativa e consiste na inserção do pesquisador no interior do grupo observado, tornando-se parte dele, interagindo por longos 
períodos com os sujeitos, buscando partilhar o seu cotidiano para sentir o que significa estar naquela situação. (QUEIROZ et al 2007, p. 278).

Entendemos, conforme mencionam as autoras citadas acima, que a coleta dos dados da pesquisa participante envolve em geral (e na linguística em particular) um tempo largo, através do qual o pesquisador tem a chance de conhecer melhor o universo de seu objeto de estudo. Em nosso caso, como somos professores do universo observado, aproveitamos não apenas nossas observações, fruto de nossas interações realizadas nas viagens de campo, como também lançamos mão de nossa experiência profissional, validando nosso compartilhamento com a realidade pesquisada, como forma de melhor interpretá-la.

A investigação teve um alcance de estudo de caso descritivo (GIL, 2006, p. 73), porque esse nível de pesquisa tem como objetivo a "descrição das características de determinada população ou fenômeno ou estabelecimento de relações entre variáveis", que é o caso da Comunidade Pisasu Sarusawa que foi estudada. N e s s e sentido, se desenvolveu o estudo de caso descritivo, pois foram analisadas e descritas as práticas de ensino-aprendizagem dos alunos, identificaram-se as estratégias pedagógicas de ensino do professor, bem como, se descreveu como se dá a prática do ensino-aprendizagem da língua nheengatu trazendo à luz dados e indicadores sobre o ensino-aprendizagem dessa comunidade indígena do rio Negro, Manaus, Amazonas.

O universo da pesquisa foi o estudo da língua nheengatu na comunidade Pisasu Sarusawa, e a população estudada correspondeu a cento e vinte oito (128) informantes da comunidade indígena, de etnia Baré, localizada na Zona Ribeirinha do baixo rio Negro, município de Manaus, AM, que representa 100\% dos indivíduos da comunidade, sendo cinco (5) professores indígenas, oitenta e três (83) alunos indígenas e quarenta (40) comunitários indígenas, com abordagem do método qualitativo, com amostragem por tipicidade ou intencional, que consistiu em selecionar um subgrupo da população potencialmente representativo. Para Vergara e Peci (2003) , a amostra por seleção é utilizada de forma não probabilística, aumentando consideravelmente as possibilidades de que a totalidade da realidade construída seja exposta ao pesquisador, e este analisa as bases e realidades que formam o universo de pesquisa e as suas relações causais.

$\mathrm{Na}$ amostragem por "tipicidade ou intencional" Gil (2006), foram coletadas informações sobre o processo de ensino aprendizagem da língua nheengatu na comunidade Pisasu Sarusawa. 
Educação escolar indígena: um estudo sociolinguístico do nheengatu na comunidade Pisasu Sarusawa do rio Negro, Manaus, AM

Para coleta de informações de pesquisa de campo, seguiu-se a estrutura de Tarallo (2003, p. 17-27), o método de "entrevista sociolinguística", e Dell Hymes (1972, p. 65), que propôs um modelo de observação bastante conveniente, o "paradigma speaking". Os dados foram coletados através de três questionários previamente elaborados, com perguntas conforme o objetivo da pesquisa, seguindo a estratificação de faixa etária e a etnicidade, assim como questões educacionais estabelecida no estudo. De acordo com a faixa etária, observamos também o comportamento de cada entrevistado, a fim de avaliarmos a veracidade dos dados emitidos pelos sujeitos da pesquisa, uma vez que, enquanto conhecedor da realidade local (sendo professor no município), estava apto a checar dados objetivos encontrados na coleta.

A construção dos questionários foi pensada a partir dos objetivos que se pretendia alcançar com a pesquisa. O questionário do Professor, aplicado aos 5 educadores, foi dividido em três partes: 1- Perguntas como, etnia, nome da comunidade, nome da escola, número de alunos e número de falantes da língua nheengatu; 2- Sobre o plano de ensino da língua nheengatu; 3- As práticas de aprendizagem da língua no cotidiano escolar.

O segundo questionário para alunos foi dividido em 5 partes, conforme segue: 1- Identificação: povo/etnia, data de nascimento, idade, série/ano e local de nascimento; 2- Tecnologias e meios de comunicação utilizados para se comunicar; 3- Sobre a aprendizagem da língua nheengatu; 4- As práticas de aprendizagem da língua no cotidiano escolar; 5- Materiais didáticos em língua nheengatu.

O terceiro questionário para comunitários foi dividido em 4 partes, conforme segue: 1- Perfil socioeconômico; 2- Perfil sociocultural; 3- Perfil sociolinguístico; 4- As práticas sociolinguísticas na comunidade.

A pesquisa foi realizada através de viagens a campo, nas quais foram usadas quatro estratégias para a obtenção dos dados: (a) questionário; (b) entrevista; (c) observação; e (d) experiência pessoal.

Os questionários semiestruturados foram aplicados em sala de aula a 83 alunos, com a finalidade de: a) identificar o grau de proficiência dos alunos indígenas na língua nheengatu; b) identificar o grau de bilinguismo, multilinguismo ou monolinguismo desses alunos; c) averiguar o processo de ensino da língua nheengatu desses alunos na escola; d) verificar o grau de instrução desses alunos; e) averiguar a frequência do ensino da língua nheengatu na escola. 
As entrevistas direcionadas aos professores e comunitários foram, também, orientadas por questionários semiestruturados, com o fim de: a) identificar o grau de proficiência deles na língua nheengatu; b) identificar o grau de bilinguismo, multilinguismo ou monolinguismo desses professores e comunitários; c) identificar a correlação entre grau de proficiência linguística e idade, letramento, presença de falantes nativos proficientes na família, entre outros aspectos; d) averiguar a metodologia usada pelos professores no ensino da língua nheengatu; e) verificar as estratégias de ensino, ferramentas e material dos professores indígenas; f) analisar se o ensino da língua nheengatu na escola é suficiente para a manutenção da língua na comunidade; g) averiguar se há continuação do ensino da língua nheengatu pelos pais no seio da família.

A estratégia da observação foi adotada durante todas as entrevistas, assim como no processo de preparação da pesquisa e do estabelecimento de contatos com a escola e a comunidade Pisasu Sarusawa. Por fim, fizemos uso de nossa experiência e nosso conhecimento, enquanto integrante da realidade pesquisada para balizar os dados coletados.

Considera-se que a pesquisa é relevante por contribuir para o desenvolvimento científico da região, através dos seguintes desdobramentos: favorecer a produção de dados técnicos e científicos que descrevam a situação sociolinguística da língua pesquisada e que instrumentalizem os professores, alunos e pais, para que possam deles se servir no processo de valorização de sua língua, aperfeiçoando e fomentando o ensino da mesma na escola e nos espaços culturais da comunidade.

Atualmente, os falantes do nheengatu, dentre os quais professores, alunos e comunitários, demonstram interesse em continuar falando a sua língua e, sobretudo, em ter uma escrita normatizada para facilitar o ensino formal da língua, o que inclui a produção de literatura em nheengatu. Para tanto, é necessário que essa língua seja valorizada, respeitada e estudada cada vez mais. Dessa forma, um estudo que evidencie a situação dessa língua nas comunidades que a falam pode contribuir para a manutenção e revitalização dela e evitar seu desaparecimento.

Por fim, entende-se que o estudo sociolinguístico nos possibilita examinar todos os aspectos da relação entre língua e sociedade (CRYSTAL, 1998, p. 243). Portanto esta pesquisa poderá ajudar a entender os desafios para a valorização e o fortalecimento da língua pesquisada, o que confirma sua relevância. Dessa forma, se pode elencar como principais contribuições deste estudo: 
a) Fornecer um diagnóstico da situação sociolinguística das comunidades bilíngues no município de Manaus, AM, que abrirá caminhos para o desenvolvimento de futuras análises sobre fenômenos linguísticos marcados por condicionantes sociais dos falantes das línguas indígenas, contribuindo ainda para o aprofundamento do conhecimento científico acerca, principalmente, da língua nheengatu e das mudanças ocorridas ao longo de sua história;

b) Subsidiar o desenvolvimento de artigos voltados para a formulação e a prática de políticas linguísticas que contribuam para a melhoria do ensino da língua nheengatu nas escolas e espaços culturais indígenas, visando ao fortalecimento do seu uso no seio das comunidades que a falam;

c) Servir de base de apoio às políticas públicas e linguísticas por parte do estado, incluindo as secretarias de educação e escolas, bem como para a definição de práticas que permitam o exercício da cidadania indígena, recuperando os indígenas na formulação e execução de programas de ensino voltados para as reais necessidades de sua cultura e línguas nativas, principalmente, no que diz respeito à concretização e ao cumprimento do ensino das línguas indígenas que ganham força com a legislação que norteia a educação escolar indígena, a partir das Resoluções n. 99/97 e n. 11/2001, do CEE/AM, Art. 3 - Inciso III, que trata do "ensino ministrado nas línguas maternas das comunidades indígenas atendidas como uma das formas de preservação sociolinguística de cada povo".

d) E, finalmente, servir de fonte de referência e de conhecimento científico aos demais pesquisadores e instituições científicas sobre a situação da língua nheengatu falada nas comunidades indígenas bilíngues do município de Manaus.

\section{O POVO BARÉ DA COMUNIDADE PISASÚ SARUSAWA: HISTÓRIA E ASPECTOS SOCIOLINGUÍSTICOS}

\subsection{Aspectos históricos}

A história do povo Baré da comunidade Pisasú Sarusawa é resultado do processo de migração dos povos indígenas no Amazonas, o qual ocorreu, segundo Bessa Freire (2003, p. 129), a partir do Decreto de 24 de julho de 1845, do primeiro governador da Província do Amazonas, Bento de Figueiredo de Tenreiro Aranha, sob o qual os indígenas de diferentes etnias, inclusive Baré foram regularmente mandados para Manaus para trabalhar sem pagamento na construção das casas da capital. 
Com o novo Diretório, os indígenas foram submetidos ao trabalho obrigatório, acabando por perderem todos os seus direitos. Uma das tarefas principais dos diretores dos indígenas era convencê-los, via de regra, pela força, a se deslocarem para os povoados e vilas coloniais, onde serviam de mão de obra nos trabalhos de construção ou extração de recursos naturais, conforme destaca Cabalzar (1998, p. 85). Esse processo levou, no século XIX, a um esvaziamento de muitas comunidades indígenas dos rios Uaupés, Içana e Xié, cujas famílias eram levadas à força para o baixo e médio rio Negro. Muitos indígenas foram envolvidos na exploração extrativista e submetidos a trabalhos compulsórios. Esse procedimento deu início a uma migração forçada, sobretudo do povo Baré. Essas migrações intensificaram-se, principalmente entre os anos 60, 70 e 80, e o principal motivo que contribuiu para esse fato foi o fechamento dos internatos salesianos entre os anos de 1984 a 1987 de Pari Cachoeira, no Tiquié, de lauareté e Taracuá no rio Uaupés, de Assunção no rio Içana, dentre outros na região entre Santa Isabel do Rio Negro e de São Gabriel da Cachoeira. Com isso, as famílias indígenas se viram obrigadas a mudar-se para as missões e, principalmente, para as cidades, para possibilitar aos seus filhos o acesso às escolas (FOIRN-ISA, 2006). Dessa forma,hoje se encontram famílias do povo Baré residindo em todas as cidades da região do rio Negro e em pequenas comunidades e vilas às margens dos rios e afluentes dessa região. Desses movimentos migratórios, surge a comunidade Pisasú Sarusawa.

Localizada à margem esquerda do rio Cuieiras afluente do rio Negro, a 180 $\mathrm{Km}$ da cidade de Manaus, AM, conforme mostra o mapa cartográfico na Figura 1, a Comunidade Pisasú Sarusawa (Nova Esperança), do povo Baré, está situada na Mesorregião do Centro Amazonense, Microrregião Manaus, no baixo rio Negro, na divisa com o município de Novo Airão, estado do Amazonas, Brasil. 
Educação escolar indígena: um estudo sociolinguístico do nheengatu na comunidade Pisasu Sarusawa do rio Negro, Manaus, $A M$

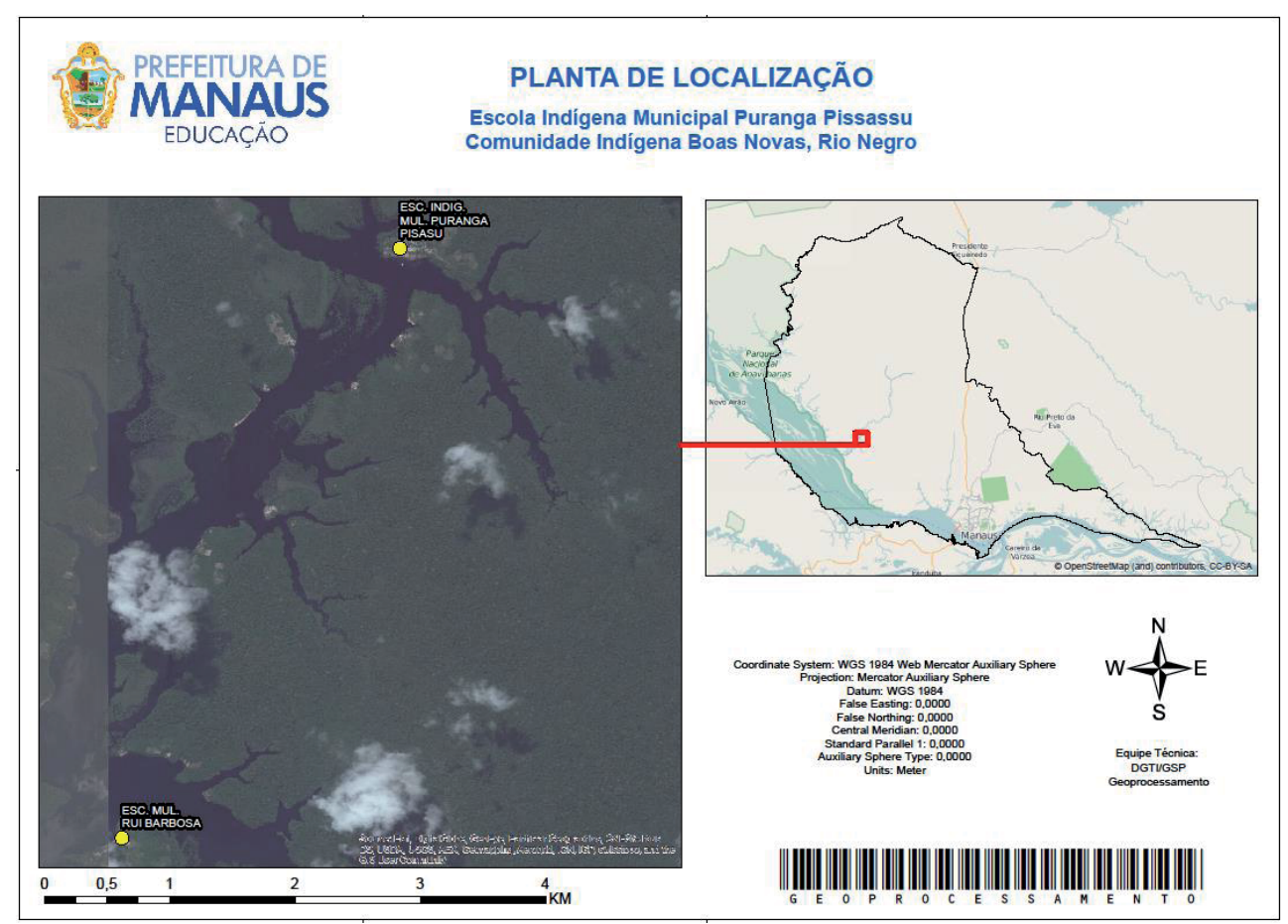

Figura 1- Planta de localização da comunidade Pisasú Sarusawa Fonte: Centro de Mídia - SEMED (MANAUS, 2016).

De acordo com Cabalzar (1998, p. 33), o termo "comunidade" é o nome dado há décadas pelos missionários católicos e adotado também pelos protestantes aos povoados que vieram a substituir as antigas malocas comunais, que eram grandes casas que serviam de moradia para várias famílias que ocupam as margens dos rios, dentre elas, a comunidade Pisasú Sarusawa.

Essa comunidade foi fundada nos anos 60 pelo Senhor Getúlio Nascimento da Silva, de etnia Baré, que, no início de sua fundação, contava com poucas famílias, que formavam um grupo de 13 pessoas, oriundas de São Gabriel da Cachoeira e de Santa Isabel do rio Negro. No decorrer dos anos 1970, 1980, 1990 e no período de 2000 a 2016, a comunidade foi recebendo outras famílias, também vindas de Santa Isabel do rio Negro, as quais foram se instalando na localidade e, com isso, aos poucos, a população foi aumentando, assim como a aldeia, na medida em que foram surgindo novas construções de casas de palafitas para abrigarem os recentes moradores. Atualmente, a comunidade Pisasú Sarusawa possui uma população es- 
timada em 128 pessoas (LIMA, 2016), na sua totalidade da etnia Baré, constituídas em 29 famílias, distribuídas em 24 casas às margens do rio Cuieiras, na região do Rio Negro, Manaus, Amazonas.

Devido ao aumento demográfico dos últimos anos, a comunidade Pisasú Sarusawa também teve que expandir sua estrutura física e de serviços sociais para atender à população. Hoje conta com uma escola pública municipal que oferece ensino básico de Educação Infantil, Ensino Fundamental de 1음o 9ㅇano, Educação Escolar Indígena e Ensino Médio Mediado por Tecnologia, além de um posto de saúde coordenado pela Secretaria Municipal de Saúde de Manaus (SEMSA), um centro social comunitário, uma biblioteca comunitária, um restaurante comunitário, um campo de futebol, uma quadra de areia e duas pequenas redes de comércios. Também, dispõe de um poço artesiano, o qual fornece água potável à comunidade, energia elétrica advinda de um grupo gerador e uma antena de captação e recepção de sinal de internet para uso nas aulas mediadas por tecnologia na escola. A taxa de nascimento é de $2 \%$ ao ano, de óbito $0,3 \%$, de crescimento demográfico $4 \%$ e o Índice de Desenvolvimento Humano (IDH) é de 0,538. Abaixo da média do IDH do município, que é de 0,720 de acordo com Censo do IBGE (2010). A expectativa de vida da comunidade é de 72,6 anos.

Embora com fortes ameaças à globalização, a comunidade Pisasú Sarusawa busca preservar e manter suas tradições, cultura e língua étnica.

\subsection{Aspectos sociolinguísticos}

Com o propósito de estudar o tema Educação Escolar Indígena, em especial o ensino-aprendizagem da língua Nheengatu no âmbito da escola indígena Puranga Pisasú, buscou-se, assim, dialogar com o universo teórico da Sociolinguística, pois este estudo se inseriu no campo que trata dos aspectos sociais que constituem o ambiente e as condicionantes para a existência e a revitalização da língua indígena. Por essa razão, recorreremos a conceitos no âmbito desse ramo da ciência linguística que nos fundamentou para a realização deste trabalho de pesquisa, principalmente os estudos de Labov (2008), Tarallo (2003), Bortoni-Ricardo (2004), Dell Hymes (1970; 1972), Calvet (2002), Romaine (1995), Braggio (2012), Hanks (2008) e outros.

A Sociolinguística é o ramo da Linguística que busca estudar os variados aspectos da relação entre língua e sociedade (CRYSTAL, 1998, p. 243). Trata-se de um termo relativamente novo e comumente empregado para se referir a uma área de 
pesquisa que faz a ligação da linguística com a antropologia e a sociedade, segundo Boas (2010). Para Calvet (2002, p. 78), a sociolinguística também se ocupa da variação da língua no interior de uma comunidade de fala, além dos aspectos estritamente geográficos, os quais já vinham sendo pesquisados há gerações pelos estudiosos da área de geografia dialetologia (DUBOIS, 1973, p. 561).

A sociolinguística é uma das vertentes teóricas da linguística, cujo propósito é averiguar a língua com foco maior nos falantes no seio das comunidades de fala, considerando os aspectos sociais norteadores do sujeito (TARALLO, 1999, p. 89). Meilllet (1921 apud CALVET, 2002, p. 17) definiu a língua como fato social. O autor aborda as diversas correntes filosóficas a respeito dos fenômenos sociolinguísticos e deixa evidente a importância de se considerar, nos estudos linguísticos, a afirmação de que, "[...] se a língua é um fato social, a linguística então só pode ser uma ciência social", conquanto sua segmentação de fato se tenha dado a partir da publicação das pesquisas de William Labov sobre o inglês falado na ilha de Martha's Vineyard em 1963, no município de Dukes, estado de Massachusetts (LABOV, 2008, p. 22). Em seus estudos, ele baseou-se nos registros do trabalho de Guy Lowman - Linguistic Atlas of New England.

Entre os fenômenos estudados na comunidade Pisasú Sarusawa, no viés da sociolinguística foi o de bilinguismo, o qual também é crucial para o nosso estudo. Adotamos a definição do termo que diz respeito à competência de um indivíduo de falar duas ou mais línguas, utilizando-as alternadamente, segundo os meios ou as situações sociocomunicativas nas quais se encontra (TRASK, 2008, p. 47). Para Braggio (2012, p. 160) "[...] um indivíduo bilíngue é aquele que usa (fala) duas línguas no seu cotidiano e, portanto, tem conhecimento das duas línguas e sabe como usá-las em diferentes situações de interação social".

De acordo com Mackey, citado em Romaine (1995, p. 8), o bilinguismo não é um fenômeno da língua, e sim de seu uso. Por isso também a definição do termo requer a identificação de categorias que dizem respeito às instâncias e à capacidade de uso da língua por parte do indivíduo. Essa capacidade, que é variável, mostra-se evidente entre as interpretações de bilinguismo apresentadas no quadro 1 e encontradas em estudiosos citados por Romaine (1995). 


\begin{tabular}{|l|l|}
\hline Estudiosos do bilinguismo & \multicolumn{1}{c|}{ Conceitos } \\
\hline Bloomfield (1933, p. 56) & $\begin{array}{l}\text { Esse autor considera que há o bilinguismo quando o } \\
\text { indivíduo tem controle de duas línguas como falante } \\
\text { nativo }\end{array}$ \\
\hline Diebold (1964) & $\begin{array}{l}\text { Na consideração desse estudioso, a produção já não é } \\
\text { tão relevante para se definir com rigor o bilinguismo. } \\
\text { Ele fornece uma definição adicional, que chama de } \\
\text { "bilinguismo incipiente", para caracterizar o estágio } \\
\text { inicial do uso de duas línguas. }\end{array}$ \\
\hline Haugen (1953, p. 7) & $\begin{array}{l}\text { Considera que o bilinguismo começa quando o falante } \\
\text { de uma língua pode produzir enunciados plenamente } \\
\text { significativos em outra língua }\end{array}$ \\
\hline Macnamara (1967) & $\begin{array}{l}\text { Propõe que um indivíduo bilíngue é alguém que possui } \\
\text { competência mínima em uma das quatro habilidades } \\
\text { linguísticas (falar, ouvir, ler e escrever) }\end{array}$ \\
\hline
\end{tabular}

Quadro 1 - Conceitos de bilinguismo

Fonte: Romaine (1995, p. 11-12).

De acordo com Mackey (2000), para se definir o bilinguismo é preciso se considerar quatro situações:

Grau de proficiência, ou seja, o conhecimento do indivíduo sobre as línguas que ele fala. Deste modo, o conhecimento de tais línguas não precisa ser equivalente em todos os níveis linguísticos;

Função e o uso das línguas, ou seja, as situações nas quais o indivíduo faz uso das duas línguas, também devem ser objeto de estudo ao conceituar o bilinguismo.

Alternância de código, o qual deve ser estudado como frequência, em que o indivíduo alterna de uma língua a outra;

Deslocamento linguístico, de como uma língua influencia a outra e aos poucos vai tomando espaço, até se tornar dominante no cotidiano do indivíduo. (MACKEY, 2000, p. 12).

No contexto de convivência bilíngue na comunidade Pisasú Sarusawa, na qual a língua indígena disputa sua funcionalidade comunicativa com o português, que é a língua veicular e dominante, diferentes graus de bilinguismo podem ser observados com muita facilidade. Em particular, citamos os três principais que são de bilinguismo equilibrado - fluentes nas duas línguas, de semibilíngue - fala algumas palavras e expressões suficientes para se fazer entender e, de bilinguismo incipiente - compre- 
Educação escolar indígena: um estudo sociolinguístico do nheengatu na comunidade Pisasu Sarusawa do rio Negro, Manaus, $A M$

ende uma segunda língua, mas não consegue falar. Este último se aplica a muitos dos indivíduos de nossa pesquisa.

O levantamento sociolinguístico constituído com base nas informações coletadas dos questionários aplicados aos 128 informantes, conforme demonstra a Tabela 1:

Tabela 1 - Dados gerais dos informantes

\begin{tabular}{|c|c|c|c|c|c|c|c|}
\hline Informantes & Faixa etária & Sexo & Indígena & $\begin{array}{c}\text { Não } \\
\text { indígena }\end{array}$ & Profissão & $\begin{array}{l}\text { Bilíngue } \\
\text { Pt. / Ng. }\end{array}$ & Total \\
\hline $\begin{array}{l}\text { Alunos da } \\
\text { Educação Infantil }\end{array}$ & 3 a 6 anos & F $7 /$ M 6 & 13 & - & Não tem & Português & 13 \\
\hline $\begin{array}{l}\text { Alunos do } 1 \text { 으 ao } \\
50 \text { ano }\end{array}$ & 7 a 11 anos & F10 / M 12 & 22 & - & Não tem & Português & 22 \\
\hline $\begin{array}{l}\text { Alunos do } 10 \text { ao } 5 \text { o } \\
\text { ano/EJA }\end{array}$ & 16 a 48 anos & $\mathrm{F} 3 / \mathrm{M} 4$ & 7 & - & $\begin{array}{l}\text { Artesão } \\
\text { Agricultor }\end{array}$ & $\begin{array}{l}\text { Pt.5 / } \\
\text { Ng. } 2\end{array}$ & 7 \\
\hline $\begin{array}{l}\text { Alunos do } 60 \text { ao } \\
9 \text { o ano }\end{array}$ & 12 a 16 anos & F 12 / M 14 & 26 & - & Não tem & Português & 26 \\
\hline $\begin{array}{l}\text { Alunos do } 2 \text { o ano/ } \\
\text { Ensino Médio/ } \\
\text { Tecnológico }\end{array}$ & 18 a 36 anos & $\mathrm{F} 8 / \mathrm{M} 7$ & 15 & - & $\begin{array}{l}\text { Artesão } \\
\text { Agricultor } \\
\text { Outras }\end{array}$ & Português & 15 \\
\hline Professores & 32 a 59 anos & $\mathrm{F} 3 / \mathrm{M} 2$ & 5 & - & Professor & Pt. / Ng & 5 \\
\hline Comunitários & 26 a 83 anos & F 18 / M 22 & 35 & 5 & $\begin{array}{c}\text { Artesão } \\
\text { Agricultor } \\
\text { Aposentado } \\
\text { Outras }\end{array}$ & $\begin{array}{l}\text { Pt } 22 / \\
\text { Ng. } 18\end{array}$ & 40 \\
\hline Quantitativo & 3 a 83 anos & F 61 / M 67 & 123 & 5 & 67 & $\begin{array}{l}\text { Pt.103 / } \\
\text { Ng. } 25\end{array}$ & 128 \\
\hline \multicolumn{8}{|c|}{ Legenda: $\mathrm{Pt}=$ Português $\quad \mathrm{Ng}=$ Nheengatu } \\
\hline
\end{tabular}

Fonte: Lima, 2016.

A totalidade de informantes é de 128, constituídos por 13 alunos da Educação Infantil, na faixa etária de 3 a 6 anos, sendo 6 do sexo masculino e 7 do sexo feminino, 22 alunos do 10 ao 5o ano do Ensino Fundamental, entre 7 a 11 anos, sendo 12 do sexo masculino e 10 do sexo feminino, 7 alunos da Educação de Jovens e Adultos (EJA), de 1 o ao 50 ano, entre 16 a 48 anos, sendo 4 do sexo masculino e 3 do sexo feminino, 26 alunos do 6으 ao 9o ano do Ensino Fundamental, entre 12 a 16 anos, sendo 14 do sexo masculino e 12 do sexo feminino, 15 alunos do 20 ano do Ensino Médio Mediado por Tecnologia, entre 18 a 36 anos, sendo 7 do sexo masculino e 8 
do sexo feminino, 5 professores, entre 32 a 59 anos, sendo 2 do sexo masculino e 3 do sexo feminino e 40 comunitários, entre 26 a 83 anos, sendo 22 do sexo masculino e 18 do sexo feminino.

Em relação à etnia, dos 128 membros 123 são Baré e 5 não indígenas. Nos aspectos socioeconômicos, as profissões predominantes são de artesão, a qual representa $56 \%$ da comunidade, seguidos de agricultor $22 \%$, aposentado $10 \%$, Professor $7 \%$ e outras $5 \%$ da população. Nos aspectos educacionais, o grau de escolaridade predominante é o Ensino Fundamental com 68\%, Ensino Médio com 21\%, Educação Infantil com 9\%, Ensino Superior com 0,78\% e taxa de analfabetismo representa $1,22 \%$ da comunidade.

Em relação ao "repertório verbal" de seus membros (RCNEI, 1998, p. 116), "refere-se ao número de línguas usadas por um indivíduo ou grupo", a comunidade é bilíngue, fala as línguas Portuguesa e Nheengatu e a situação sociolinguística entre os falantes da língua indígena é bem heterogênea, haja vista que, de acordo com o RCNEl (1998, p. 116) "Uma mesma língua pode não ser falada exatamente do mesmo modo por todos os que a usam". É o caso da comunidade Pisasú Sarusawa, onde foram encontrados três níveis de falantes em relação ao grau de proficiência, é o que mostram os dados de pesquisa.

De acordo com o "levantamento sociolinguístico" que realizamos em 2016 e 2017, baseados no método das comparações léxico-estatísticas de Morris Swadesh (apud Dell Hymes, 1970), e do método de análise do Atlas of the wordl's language in danger (UNESCO, s.d.), por meio das técnicas de pesquisa de campo (questionário, entrevista e observação participante), coletados na comunidade Pisasú Sarusawa, apontou-se que há três níveis de falantes da língua nheengatu. Os dados de pesquisa constatam que:

- No primeiro nível, estão os "falantes fluentes" (bilinguismo equilibrado) - os quais utilizam o nheengatu na comunidade no dia a dia entre seus membros;

- No segundo nível, estão os "semifalantes" (semibilíngues) - que apenas entendem e conseguem lembrar parte do vocabulário, mas não falam nheengatu fluentemente;

- No terceiro nível, estão os "não falantes" (bilinguismo incipiente) - que não falam e apenas entendem o nheengatu. 
- As análises feitas com base no método de Swadesh e da UNESCO apontam que a situação sociolinguística entre os falantes do nheengatu na comunidade Pisasú Sarusawa apresenta os três níveis: falantes fluentes, semifalantes e não falantes. Para a UNESCO, o grau de risco é representado pelas cores verde (fora de perigo) - "a língua é falada por todas as gerações"; branco (vulnerável) - "a maioria das crianças fala a língua, mas pode ser restrita a certos domínios (casa, cerimônias, etc.)"; amarelo (definitivamente em perigo) - "as crianças já não aprendem a língua como língua materna em casa"; laranja (severamente ameaçada) - "a língua é falada por avós e gerações mais velhas, enquanto as gerações mais novas não falam entre si"; vermelho (criticamente em perigo) - "somente alguns falantes mais adultos falam parcialmente e com pouca frequência"; e preto (extinta) "não há falantes".

Os dados do Gráfico 1 exemplificam bem a situação da língua nheengatu na comunidade Pisasú Sarusawa:

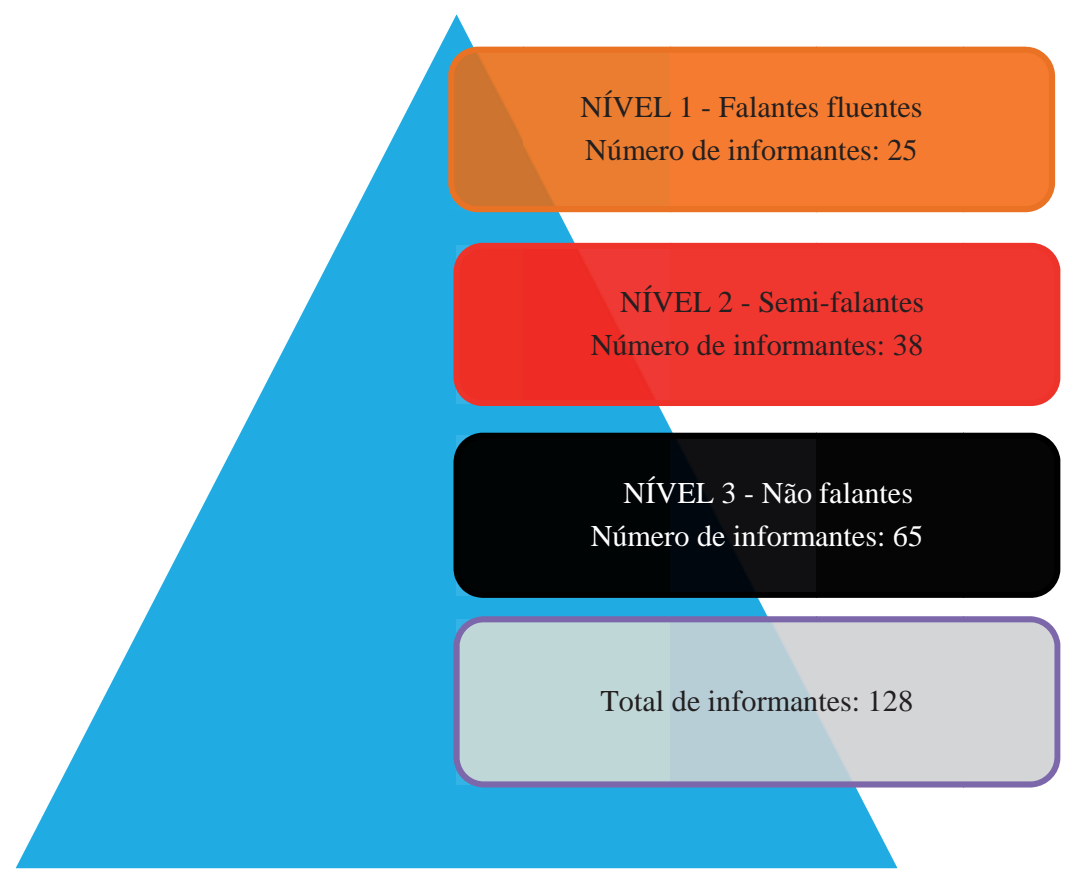

Gráfico 1 - Situação sociolinguística dos falantes de nheengatu na comunidade Pisasú Sarusawa

Fonte: Lima, 2016. 
Conforme se demonstra no Gráfico 1, o estudo aponta que no primeiro nível, onde se encontram os "falantes fluentes", os que utilizam o nheengatu na comunidade no dia a dia entre seus membros e que, para a análise da UNESCO classificam-se na cor laranja (severamente ameaçado), "a língua é falada por avós e gerações mais velhas", 25 pessoas, na faixa etária acima dos 40 anos, os quais representam 19,53\% da população da comunidade que ainda falam a língua indígena. No segundo nível, estão os "semifalantes", que apenas entendem e conseguem lembrar parte do vocabulário, mas não falam o nheengatu fluentemente, para a UNESCO classificam-se na cor vermelha (criticamente em perigo), "somente alguns falantes mais adultos falam parcialmente e com pouca frequência", os quais somam um total de 38 pessoas, na faixa etária entre 20 a 39 anos e que representam 29,68\%. No terceiro nível, estão os "não falantes" que não falam e apenas entendem o nheengatu, que para UNESCO classificam-se na cor preta (não há falantes), os quais somam 65 pessoas, na faixa etária entre 3 a 19 anos e representam 50, 79\% da comunidade.

\subsection{Aspectos educacionais}

O ensino na comunidade Pisasú Sarusawa é desenvolvido através do Projeto Político Pedagógico (PPP), sob o qual organiza seu planejamento e suas atividades escolares, com base na orientação dos Parâmetros Curriculares Nacionais (PCN) e do Referencial Curricular Nacional da Educação Indígena (RCNEI), com supervisão e orientação da Gerência de Educação Escolar Indígena (GEEI/SEMED) através do corpo pedagógico da (GEEI) que coordena e orienta as ações pedagógicas do ano letivo, com encontros trimestrais nas escolas indígenas.

O Projeto Político Pedagógico elaborado pela comunidade contempla todas as disciplinas regulares, os temas transversais contemporâneos e o ensino da língua nheengatu. É o instrumento que possibilita que a comunidade indígena expresse qual escola deseja, em termo de metodologia de ensino, de que forma a escola deve atender aos seus interesses sociais e culturais, como ela deve ser estruturada, e como ela se integra à vida e aos projetos comunitários. Esse documento tem amparo legal nas leis e regimentos da educação nacional, como Lei de Diretrizes e Base da Educação Brasileira (LBD n. 9.394/96), Resolução n. 5/2012 (Art. 14), Referencial Curricular Nacional da Educação Indígena (RCNEI/1997), assim como no documento da Fundação Nacional do Índio (FUNAI, s.d. ), que serve de base para a elaboração do PPP, no qual se devem considerar os seguintes aspectos: 
Educação escolar indígena: um estudo sociolinguístico do nheengatu na comunidade Pisasu Sarusawa do rio Negro, Manaus, AM

a) A necessidade de assegurar os direitos à educação diferenciada aos povos indígenas e à valorização de suas línguas, conhecimentos e processos pedagógicos próprios;

b) O entendimento de que o currículo compõe o todo do fazer escolar, e não apenas a organização da matriz onde se abrigam as disciplinas, assim como o PPP se constitui como elemento estruturante da vida escolar que expressa a identidade e os projetos societários. A escola indígena deve refletir o modo de vida, a concepção cultural e política de cada povo indígena e as relações intersocietárias que mantém;

c) O papel da escola na vida da comunidade, sua articulação com as demais ações e projetos do povo indígena, assim como sua influência em outras áreas de atuação dos governos, tendo como pressuposto, portanto a necessidade do tratamento integrado de questões de territorialidade, sustentabilidade e patrimônio cultural. (FUNAI, 2015).

A Resolução n. 5/2012, no (Art. 1ㅇ) define que as "Diretrizes Curriculares Nacionais estão pautadas pelos princípios da igualdade social, da diferença, da especificidade, do bilinguismo e da interculturalidade, fundamentos da Educação Escolar Indígena". Assim, o PPP da escola indígena da comunidade Pisasú Sarusawa dar ênfase a essas características, como princípio norteador de funcionalidade e aplicabilidade no âmbito escolar.

Além do conteúdo das disciplinas regulares, a escola da comunidade trabalha concomitantemente com os Temas Sociais Contemporâneos (relacionados a um contexto político e social específico, ancorado na vivência histórica particular da comunidade), os quais se articulam com os componentes curriculares e as áreas de conhecimento através da interdisciplinaridade. Temas como terra e conservação da biodiversidade, direito, lutas e movimentos, saúde e educação, pluralidade cultural, vida familiar e social, assim como os direitos das crianças e dos adolescentes, de acordo com o Estatuto da Criança e do Adolescente, preservação do meio ambiente, nos termos da política nacional de educação ambiental (Lei n. 9.795/99), educação para o consumo, educação fiscal, trabalho, ciência e tecnologia permeiam o desenvolvimento dos conteúdos da base nacional comum e da parte diversificada do currículo (Art. 16 da Resolução n. 07/10/CNE/CEB) e o $§ 1$ ㅇque especifica a inclusão o direito dos idosos (Lei n. 10.741/2003) e a Educação para o Trânsito (Lei n. 9.503/97). Esses temas sociais contemporâneos propostos pela Base Nacional Curricular Comum (BNCC), em concomitância com o Programa Curricular da Secretaria Municipal de Educação e executado pela escola, através do Projeto Político Pedagógico (PPP) são 
atividades educacionais complementares, que levam em consideração a realidade da comunidade.

As práticas avaliativas são múltiplas e contínuas, com caráter formativo e não eliminatório. Os instrumentos são variados e flexíveis e levam em consideração a produção oral, escrita, participativa e assídua do alunado, possibilitando a interpretação e uso de diferentes códigos e linguagens para a expressão da aprendizagem. Para estimular esses momentos reflexivos são acionados pelos professores e alunos processos como debates, entrevistas, análise das produções ao longo do ano letivo, resolução de problemas, o diário de classe dos professores, os relatórios de alunos e a autoavaliação.

Desse modo, a Educação Escolar Indígena oferecida na comunidade Pisasú Sarusawa mostra-se como uma das principais ferramentas pedagógicas de ensino da língua nheengatu e visa revitalizá-la na comunidade, assim como também manter vivas as culturas e tradições do povo indígena dessa comunidade.

\section{CONSIDERAÇÕES FINAIS}

Neste estudo de pesquisa, buscou-se descrever a situação sociolinguística do ensino da língua nheengatu, a partir das políticas linguísticas que trata desse assunto no município de Manaus, por meio de abordagem quali-quantitativa, de pesquisa de campo e estudo descritivo. O estudo mostrou ainda, com base nos estudos realizados, a situação sociolinguística do ensino da língua nheengatu na comunidade Pisasú Sarusawa do município de Manaus, embasado em estudos que fundamentam as políticas linguísticas na educação escolar indígena, em especial, no espaço escolar da comunidade, com base nos estudos do bilinguismo e nas práticas escolares voltadas para o ensino da revitalização da língua nheengatu e de discussão sobre a situação sociolinguística para a manutenção da língua indígena como elemento de construção da identidade cultural do povo Baré, do município de Manaus.

As hipóteses levantadas na pesquisa sobre o processo de ensino da língua nheengatu na comunidade Pisasú Sarusawa, do município de Manaus, como meio para a revitalização da língua, as estratégias pedagógicas de ensino da língua nheengatu, como ferramentas no processo de ensino-aprendizagem dos discentes, e as práticas do ensino-aprendizagem da língua nheengatu, como meio para evitar o fenômeno de deslocamento sociolinguístico na comunidade Pisasú Sarusawa do rio Negro, Manaus, são afirmativas, visto que esse ensino oferecido pela escola 
mostrou-se como a principal alternativa de manutenção e revitalização do nheengatu na comunidade, haja vista que a língua indígena já não é mais transmitida de geração a geração no seio familiar, e sua prática restringe-se a pouco mais de 19\% dos membros da comunidade. Desse modo, a proposta de estudo desenvolvida nesta pesquisa se orienta também para a compreensão do papel histórico-social desempenhado pelo nheengatu no processo de construção social da "identidade coletiva indígena", protagonizado pelo movimento de emergência étnica verificado na comunidade Pisasú Sarusawa. Ou seja, o enfoque analítico mostrou que o "ensino da língua indígena no espaço escolar" tem por finalidade afirmar sua importância como meio de manutenção e revitalização e, consequentemente, implica também o desvendamento dos significados historicamente atribuídos ao nheengatu, tanto no passado histórico quanto na contemporaneidade.

Nessa perspectiva, o objetivo principal da pesquisa em analisar como se dá o processo de ensino-aprendizagem da língua nheengatu no espaço escolar da comunidade Pisasú Sarusawa do rio Negro, Amazonas, foi fundamental para se entender o contexto do processo de ensino da educação escolar indígena na comunidade, o qual promove os conhecimentos indígenas e valorização da cultura, bem como formar cidadãos que respeitem e preservem suas tradições e línguas, ajudando na preservação étnica de sua comunidade.

Em relação aos objetivos mais específicos de como investigar o processo de ensino-aprendizagem da língua nheengatu, identificar as estratégias pedagógicas de ensino da língua, descrever como se dá a prática do ensino-aprendizagem da língua nheengatu e averiguar o grau de manutenção e/ou de revitalização na comunidade Pisasú Sarusawa do rio Negro, ficou evidente, nos estudos, que o ensino tem contribuído na recuperação do nheengatu, assim como tem mantido viva a língua indígena em meio a pressões externas de diferentes veículos de comunicação e falta de materiais didáticos e de literatura publicados em língua geral para a prática de leitura na comunidade.

Portanto o ensino oferecido na comunidade Pisasú Sarusawa do município de Manaus tem sido, eficazmente, o grande propulsor na manutenção e revitalização da língua nheengatu ao povo Baré dessa comunidade que usa essa língua como meio de expressar seus sentimentos, memórias, culturas e tradições a toda sociedade brasileira. 


\section{REFERÊNCIAS}

AMAZONAS, Estado [de]. Secretaria de Estado da Educação e Qualidade do Ensino. Resolução/ CEE/AM n. 11, de 13 de fevereiro de 2001. Normas para criação e funcionamento da escola indígena, autorização e reconhecimento de cursos, no âmbito da educação básica no estado do Amazonas, e da outras providências. Manaus: CEE, 2001.

. Secretaria de Estado da Educação. Resolução/CEE/AM n. 99, de 19 de dezembro de 1997. Estabelece normas regulamentares para implantação do Regime instituído pela Lei $n$. 9.394/96, no Estado do Amazonas. Manaus: CEE, 1997.

BESSA FREIRE, José Ribamar. Da língua geral ao português: para uma história dos usos sociais das línguas na Amazônia. 2003. 239f. Tese (Doutorado em Literatura Comparada)- Universidade Estadual do Rio de Janeiro, Rio de Janeiro, RJ, 2003.

BOAS, Franz. Antropologia cultural. Tradução de Celso Castro. 6. ed. Rio de Janeiro: Zahar, 2010.

BORTONI-RICARDO, Stella Maris. Educação em língua materna: a sociolinguística em sala de aula. São Paulo: Parábola, 2004.

BRAGGIO, Silvia Lúcia Bigonjal. As diferentes situações sociolinguística e os tipos de empréstimos na adição do português ao xerente akwén: fatores positivos e negativos. Liames, Campinas, v. 12, p. 157-77, 2012.

BRASIL. Constituição Federal da República Federativa do Brasil. Brasília: Congresso Nacional, 1988.

. Lei de Diretrizes e Bases da Educação Nacional: (9.394/96). Apresentação de Carlos Roberto Jamil Cury. 4. ed. Rio de Janeiro: DP\&A, 2001.

- Ministério da Educação e do Desporto, Secretaria de Educação Fundamental. Referencial Curricular Nacional para as Escolas Indígenas (RCNEI). Brasília: MEC/SEF, 1998.

. Ministério da Educação. Resolução CNE/CEB n. 5, de 22 de junho 2012. Define Diretrizes Curriculares Nacionais para a Educação Escolar Indígena na Educação Básica. Brasília, DF: MEC/CNE/CEB, 2012.

CABALZAR, Aloísio; RICARDO, Carlos Alberto. Povos indígenas do Alto e Médio Rio Negro: uma introdução à diversidade cultural e ambiental do noroeste da Amazônia brasileira. São Paulo: ISA; São Gabriel da Cachoeira, AM: FOIRN, 1998.

CALVET, Louis-Jean. Sociolinguística: uma introdução crítica. Tradução de Marcos Macionilo. São Paulo: Parábola, 2002.

CRYSTAL, David. Dicionário de linguística e fonética. Rio de Janeiro: Jorge Zahar, 1998.

DUBOIS, Jean et al. Dicionário de linguística. São Paulo: Cultrix, 1973. 
Educação escolar indígena: um estudo sociolinguístico do nheengatu na comunidade Pisasu Sarusawa do rio Negro, Manaus, $A M$

FEDERAÇÃO DAS ORGANIZAÇÕES INDÍGENAS DO RIO NEGRO; INSTITUTO SOCIOAMBIENTAL (FOIRN-ISA). Povos Indígenas do alto e médio Rio Negro: uma introdução à diversidade cultural e ambiental do noroeste da Amazônia brasileira. Brasília: MEC/SEF, 2006.

FUNDAÇÃO NACIONAL DO ÍNDIO (FUNAI). Educação Escolar Indígena. [s.d.]. Disponível em: <http://www.funai.gov.br/index.php/educacao-escolar-indigena>. Acesso em: 10 out. 2015.

GIL, Antônio Carlos. Métodos e técnicas de pesquisa social. 5. ed. São Paulo: Atlas, 2006.

HANKS, William F. Língua como prática social: das relações entre língua, cultura e sociedade a partir de Bourdieu e Bakhtin. São Paulo: Cortez, 2008.

HYMES, Dell. Foundations in sociolinguistics: an ethnographic approach. Philadelphia: University of Pennylvania Press, 1972.

Morris Swadesh. Journal Word, v. 26, n. 1, p. 119-38, 1970. DOI: http://dx.doi.org/ 10.1080/00437956.1970.11435588.

INSTITUTO BRASILEIRO DE GEOGRAFIA E ESTATÍSTICA (IBGE). [s.d.]. Disponível em: <http:// cod.ibge.gov.br/3WL/>. Acesso em: 29 out. 2016.

LABOV, William. Padrões sociolinguísticos. Tradução de Marcos Bagno. São Paulo: Parábola, 2008.

LIMA, Ademar dos Santos. Educação escolar indígena: um estudo sociolinguístico do nheengatu na escola Puranga Pisasú do rio Negro, Manaus, AM. 2016. Dissertação (Mestrado em Letras e Artes) - Universidade do Estado do Amazonas (UEA), Manaus, AM, 2016

MACKEY, Willian. The description of bilingualism. In: WEI, Li. The bilingualism reader. London, New York: Routledge, 2000.

MANAUS, Cidade [de]. Secretaria Municipal de Educação. Planta de localização da comunidade Pisasú Sarusawa. Manaus: Centro de Mídia, 2016.

. Decreto n. 90/2009. Cria Gerência de Educação Escolar Indígena (GEEI). Manaus: Rede Municipal de Ensino, 2009.

MELGUEIRO, Zilma Henrique. A situação sociolinguística nas escolas indígenas Irmã Inês Penha e Dom Miguel Alagna na cidade de São Gabriel da Cachoeira - AM. 2012. Dissertação (Mestrado em Letras) - Universidade Federal de Pernambuco, Pernambuco, BA, 2012.

PACHECO, Frantomé Bezerra. Análise da produção sobre as línguas dos povos indígenas do Amazonas. In: SANTOS, Gilton Mendes (Coord.). Amazonas indígena: um mapeamento das instituições e da produção bibliográfica sobre os povos indígenas no estado. Relatório final. Manaus: FAPEAM, 2009.

PINHEIRO, Aquiles Santos. Identidade, língua e cultura: usos sociais e políticos do Nheengatu na comunidade indígena do Cartucho, no Médio Rio Negro - AM, 2011. Dissertação (Mestrado em Antropologia Social)- Universidade Federal do Amazonas, Manaus, AM, 2011. 
POSTO de saúde comunitário Uka Yane Pusanga. Comunidade Pisasú Sarusawa. Manaus: SEMSA, 2016.

PROJETO Político Pedagógico. Escola Municipal Puranga Pisasu, Manaus, 2015.

QUEIROZ, D. T.; VALL, J.; SOUZA, A. M. A. ; VIEIRA, N. F. C. Observação participante na pesquisa qualitativa: conceitos e aplicações na área da saúde. Revista Enfermagem, Rio de Janeiro, v. 15, n. 2, p. 276-83, abr./jun. 2007.

RENAULT-LESCURE, Odile. As línguas faladas pelas crianças do Rio Negro, Amazonas: descontinuidade na transmissão familiar das línguas. In: FRANCO, Heliana Brito Franco; LEAL, Maria de Fátima Mendes (Org.). Crianças na Amazônia: um futuro ameaçado. Belém: Universidade Federal do Pará/UNICEF, 1990. p. 315-24.

ROMAINE, Suzanne. Bilinguism. Cambridge, Mass: Blackwel, 1995.

TARALLO, Fernando. A pesquisa sociolinguística. 7. ed. São Paulo: Ática, 2003.

TRASK, R. L. Dicionário de linguagem e linguística. São Paulo: Contexto, 2008.

ORGANIZAÇÃO DAS NAÇÕES UNIDAS PARA A EDUCAÇÃO, A CIÊNCIA E A CULTURA (UNESCO). Interactive Atlas of the World's Languages in Danger. [s.d.]. Disponivel em: <http:// www.unesco.org/languages-atlas/index.php/>. Acesso em: 4 out. 2016.

VERGARA, S. C.; PECI, A. Escolhas metodológicas em e estudos organizacionais. Organizações \& Sociedade, Salvador, v. 10, n. 27, p. 13-26, 2003.

\section{Sobre os autores:}

Ademar dos Santos Lima: Mestrando no Programa de Pós-Graduação em Letras e Artes da Universidade do Estado do Amazonas (UEA). Bolsista PROGRAD-FAPEAM/QUALIFICA-SEMED. Graduado em Letras Línguas Portuguesa e Inglesa pela Universidade Federal do Amazonas (UFAM), Manaus, Amazonas, Brasil. E-mail: ademarlima7@hotmail.com

Silvana Andrade Martins: Doutora e Pós-doutora em Letras e Linguística pela Vrije Universiteit, Amsterdam, Holanda; e mestre em Letras e Linguística pela Universidade Federal de Santa Catarina. Professora e pesquisadora do Programa de Pós-Graduação em Letras e Artes do Curso de Mestrado da Universidade do Estado do Amazonas (UEA). E-mail: andrandemartins.silvana2@gmail.com

Recebido em 27 de dezembro de 2016 Aprovado para publicação em 19 de abril 2017 